\title{
Esophageal stricture due to magnesium citrate powder ingestion: A unique case
}

\author{
A Assal MD, N Saloojee MD, H Dhaliwal MD
}

\section{CASE PRESENTATION}

A 40-year-old man presented to the emergency department with dyspnea and chest pain after ingesting one teaspoon of magnesium $(\mathrm{Mg})$ citrate powder (630 mg of elemental $\mathrm{Mg}$ ) prescribed by his naturopath for constipation. He failed to mix it with $180 \mathrm{~mL}(6 \mathrm{oz})$ of fluid as instructed on the product monograph. Potential adverse effects were not listed. He was initially treated for aspiration pneumonia but returned two weeks later with chest pain and dysphagia. Endoscopy demonstrated severe Los Angeles grade D esophagitis from $18 \mathrm{~cm}$ to the gastroesophageal junction. He was discharged with a prescription for an oral proton-pump inhibitor (PPI). Twenty-three days postingestion, he presented with progressively worsening dysphagia and odynophagia. A second endoscopy identified a caustic stricture $25 \mathrm{~cm}$ from the incisors. A $6 \mathrm{~mm}$ controlled radio expansion wire-guided balloon was used to attempt dilation but was stopped due to fresh heme and tearing. He was admitted to hospital for intravenous fluid and PPI therapy. An upper gastrointestinal barium radiograph identified a tapered narrowing initiating at $3 \mathrm{~cm}$ below the cricopharyngeus (Figure 1). The first attempt at endoscopic dilation using a $15 \mathrm{Fr}$ Savary bougie was unsuccessful due to significant transmural inflammation. Next, an ultrathin endoscope was used to pass a guidewire into the stomach and a Hurricane biliary balloon (Boston Scientific, USA) was used to sequentially dilate the stricture to $6 \mathrm{~mm}$ to $8 \mathrm{~mm}$. An $18 \mathrm{~mm} \times 170 \mathrm{~mm}$ FCSEMS (Hanarostent-Esophagus CCC, MI Tech Co Ltd, USA) was advanced via guidewire and deployed using fluoroscopic guidance (Figure 2). The patient could tolerate a full fluid diet. Subsequent endoscopies at two-week intervals identified $5 \mathrm{~cm}$ of distal stent migration, for which proximal esophageal dilation and lasso repositioning were required. Two months after initial placement, the stent was removed and the esophagus was dilated to a diameter of $15 \mathrm{~mm}$. At two follow-up endoscopies, stricturing had recurred, indicating a full-thickness stricture (Figure 3).

Surgical management was explored because his quality of life was severely affected. The surgeons performed endoscopy using a smalldiameter Savary bougie dilator to determine the suitability of the gastric mucosa for an esophageal replacement conduit. After this, he developed two areas of contained perforation; he was admitted to hospital and treated with antibiotics. Seven months after initial ingestion, he underwent esophagectomy with gastric conduit and feeding jejunostomy.

\section{DISCUSSION}

In the United States, 5000 to 20,000 caustic ingestions occur annually $(1,2)$. Primarily observed in children, a minority are encountered in the adult population and are often intentional. There are no reported cases of caustic ingestions secondary to $\mathrm{Mg}$ citrate, a weak base, in the medical literature. However, a search of the grey literature identified two personal accounts on public forums of 'inflamed esophagus' and 'burned esophagus' after ingestion of undiluted $\mathrm{Mg}$ citrate powder.

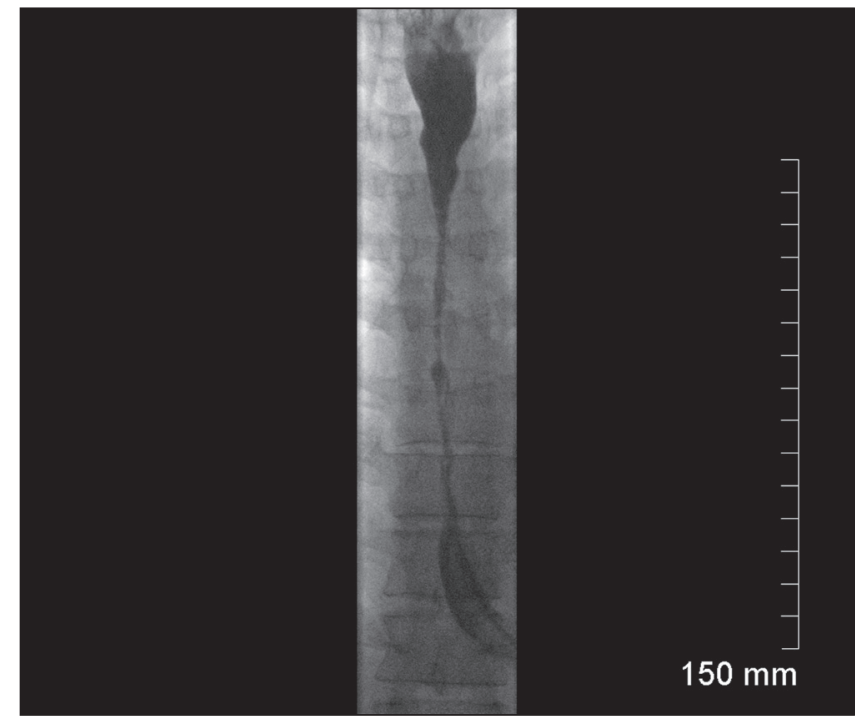

Figure 1) Barium upper gastrointestinal series: A tapered narrowing of the proximal esophagus begins $3 \mathrm{~cm}$ below the cricopharyngeus. The narrowing persists over $13 \mathrm{~cm}$ and is $2 \mathrm{~mm}$ in diameter, demonstrating long-segment stenosis of the esophagus

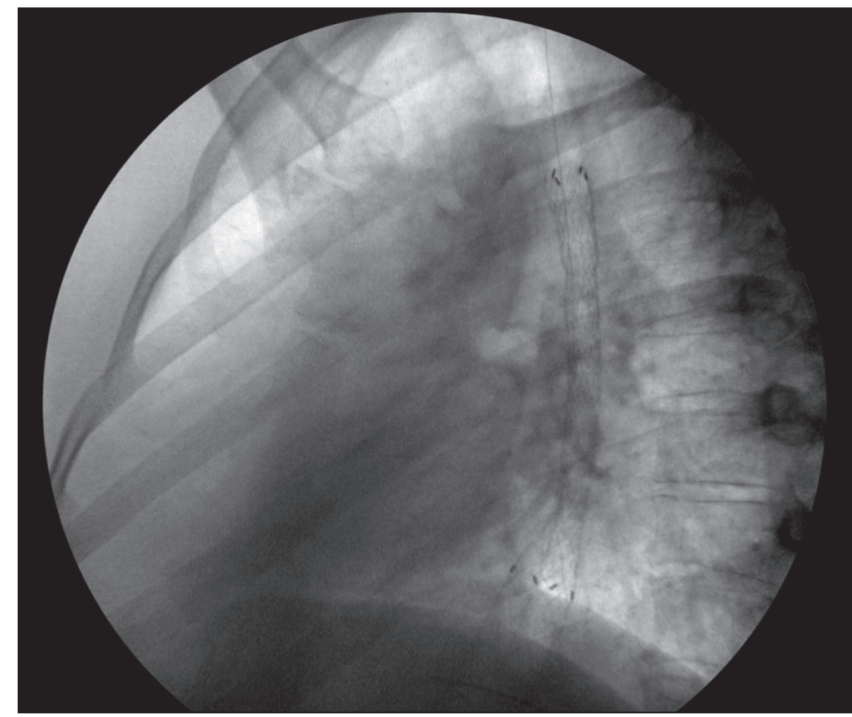

Figure 2) Fluoroscopy. Expandable metallic stent is demonstrated to be in satisfactory position after endoscopy and antegrade instrumentation of the midthoracic esophageal stricture including balloon dilation

University of Ottawa, Ottawa Hospital Research Institute, Ottawa, Ontario

Correspondence: Dr A Assal, clo Cindy Taylor, The Ottawa Hospital - General Campus - Box 210-Room 7132, 501 Smyth Road, Ottawa,

Ontario K1H 8L6. Telephone 613-722-7000, e-mail aassal@toh.on.ca

Received for publication May 15, 2014. Accepted September 17, 2014 


\section{TABLE 1}

Endoscopic grading of caustic mucosal injuries

\begin{tabular}{ll}
\hline Grade & Endoscopic findings \\
\hline 0 & Normal \\
1 & Edema and hyperemia of mucosa \\
$2 \mathrm{~A}$ & Friability, hemorrhages, erosions, blisters, whitish \\
& membranes, exudates and superficial ulcerations \\
$2 \mathrm{~B}$ & 2a plus deep discrete or circumferential ulceration \\
$3 \mathrm{~A}$ & Small scattered areas of necrosis \\
$3 \mathrm{~B}$ & Extensive necrosis \\
\hline
\end{tabular}

Data adapted from reference 4

Acidic ingestions cause a coagulative necrosis leading to eschar formation (2,3). Alkali ingestions cause liquefactive necrosis, submucosal vascular thrombosis and transmural injury $(2,3)$. Between the third week and several months after ingestion, scar retraction and stricture formation occur. An increase in gastroesophogeal reflux from altered sphincter pressure exacerbates stricture formation (3). The quantity ingested, $\mathrm{pH}$ of substance, duration of exposure and physical state of the product predict severity of disease $(2,3)$. Acute complications include mucosal injury, fistulae, perforation, mediastinitis and peritonitis, which, in rare cases, lead to death (2-4). Long-term complications include esophageal stricture, pyloric stenosis and esophageal squamous cell carcinoma.

Endoscopy should be performed within $24 \mathrm{~h}$ to assess severity of damage and prognosis; symptoms and examination are not reliable (2-4). Procedure-related perforation in early endoscopy is rare (3). The Zargar endoscopic classification is used to grade caustic mucosal injuries (Table 1) (4). Grades 0 to $2 \mathrm{~A}$ have a good prognosis, with low likelihood of stricture formation (2-4). Grades $2 \mathrm{~B}$ to $3 \mathrm{~A}$ have a very high likelihood of stricture development (70\% to $100 \%$ ) (2-4). Grade $3 \mathrm{~B}$ is associated with increased mortality and the need for surgery (2-4).

Animal studies have demonstrated benefit from steroids for prevention of stricture formation; however, human studies are inconclusive and use is only considered in grade 3 injuries $(2,3)$. Concomitant prophylactic antibiotics are recommended when treating with steroids (3). Intraluminal stents may be helpful in preventing stricture formation (3). Treatment with antacids to prevent acceleration of stricture formation by any potential reflux is recommended, although evidence is limited (3). Treatment of developed strictures includes dilation and, potentially, surgery (3).

In our case, the stent was placed early; however, it failed due to repeated migration. Repeated dilations due to recurrent stricture formation also failed and, ultimately, the patient required surgical intervention. Our case is unique because it describes a severe esophageal stricture due to $\mathrm{Mg}$ citrate ingestion that was previously unreported. The patient

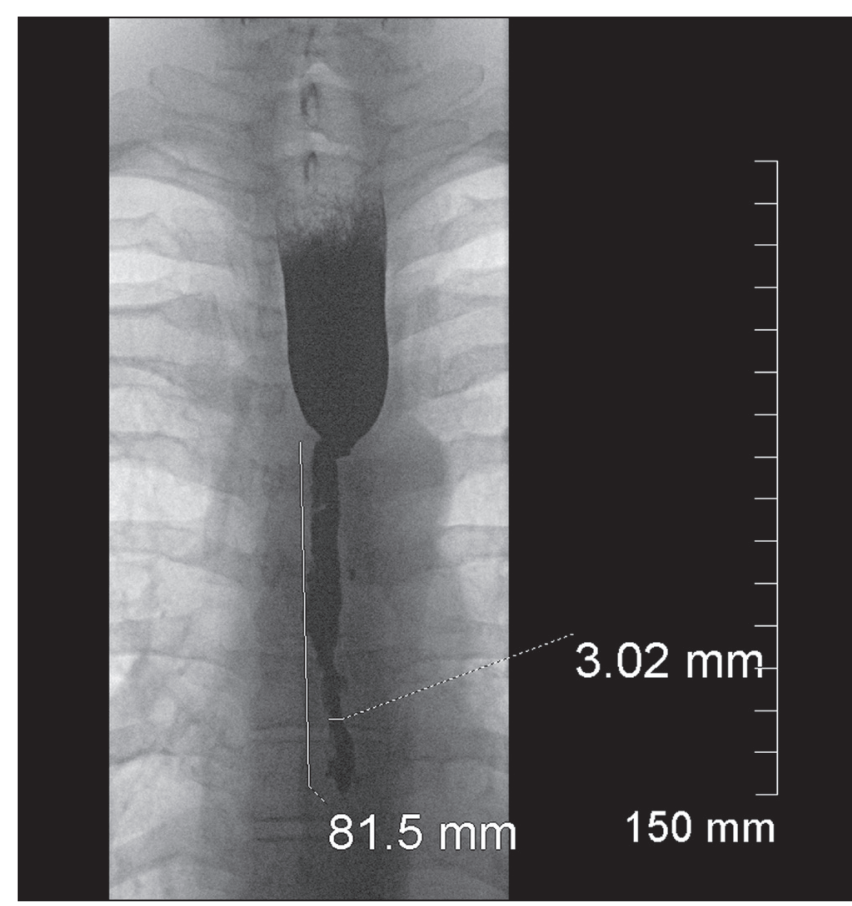

Figure 3) Barium upper gastrointestional series five months postingestion demonstrating persistent stenosis

was not made aware of the potential risks before consuming this product, nor was it listed on the product monograph. Patients should be educated about the potential for side effects from natural supplements.

DISCLOSURES: The authors have no financial disclosures or conflicts of interest to declare.

\section{REFERENCES}

1. Kikendall JW. Caustic injestion injuries. Gastroenterol Clin North Am 1991;20:847.

2. Abaskharoun RD, Depew WT, Hookey LC. Nonsurgical management of severe esophageal and gastric injury following alkali ingestion. Can J Gastroenterol 2007;21:757-60.

3. Ramasamy K, Gumaste VV. Corrosive ingestion in adults. J Clin Gastroenterol 2004;37:119-24.

4. Zargar SA, Kochhar R, Mehta S, Mehta SK. The role of fiberoptic endoscopy in the management of corrosive ingestion and modified endoscopic classification of burns. Gastrointest Endosc 1991;37:165-9

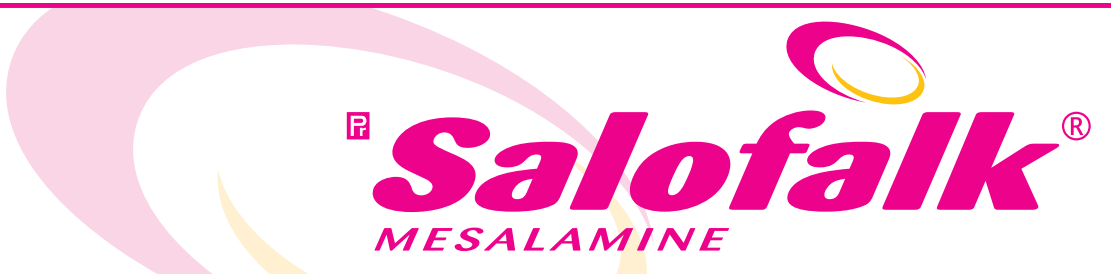

SALOFALK ${ }^{\circledR}$ is a registered trademark of Actavis Specialty Pharmaceuticals Co. or its affiliates and is used under license. (C) Actavis 2014. All rights reserved. 


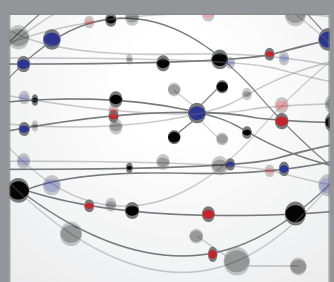

The Scientific World Journal
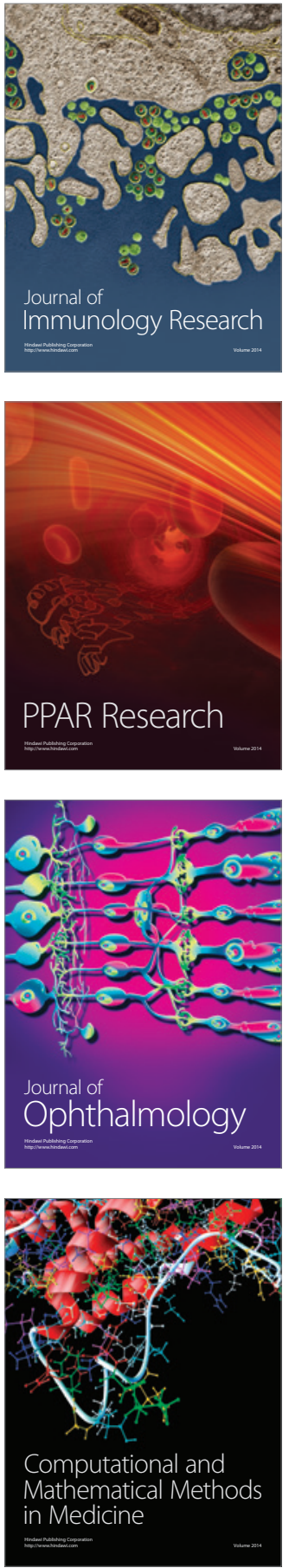

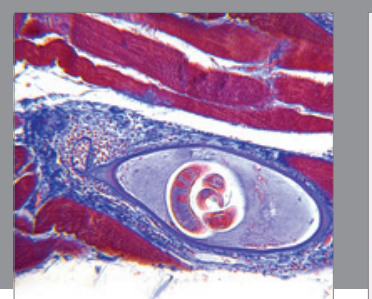

Gastroenterology Research and Practice

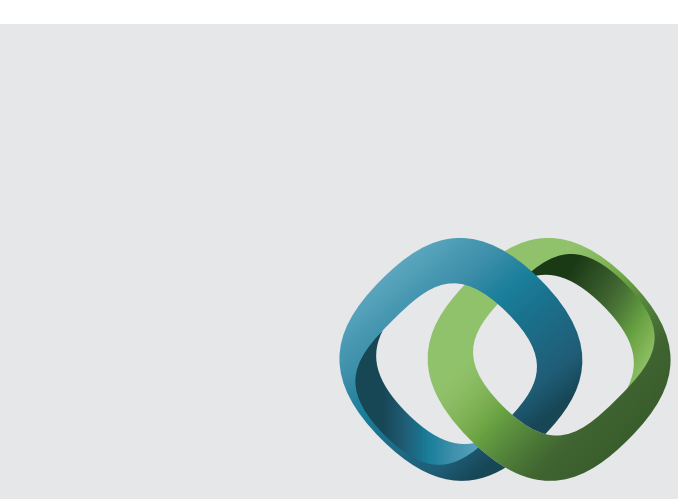

\section{Hindawi}

Submit your manuscripts at

http://www.hindawi.com
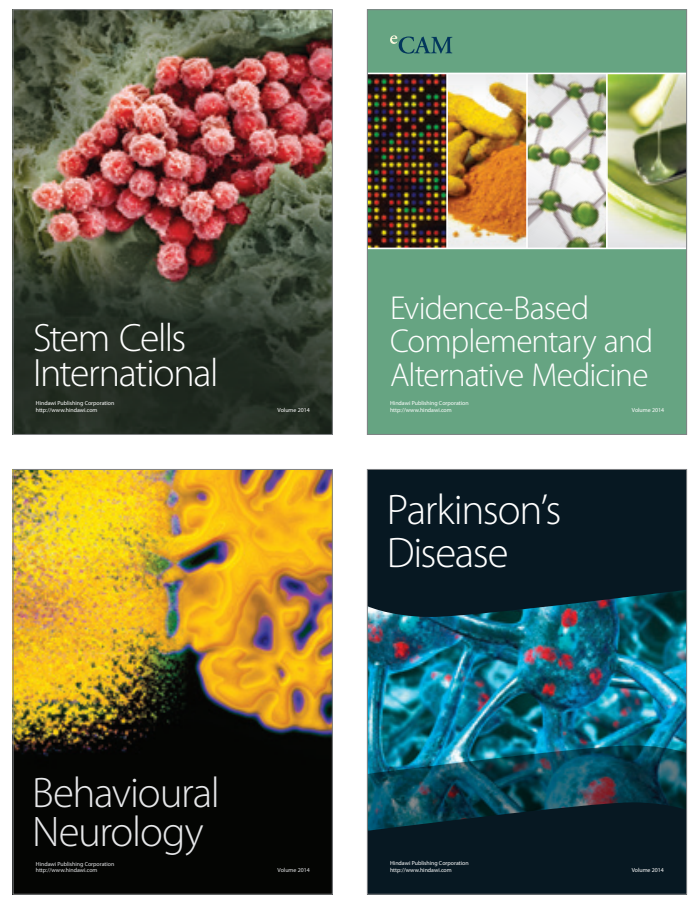
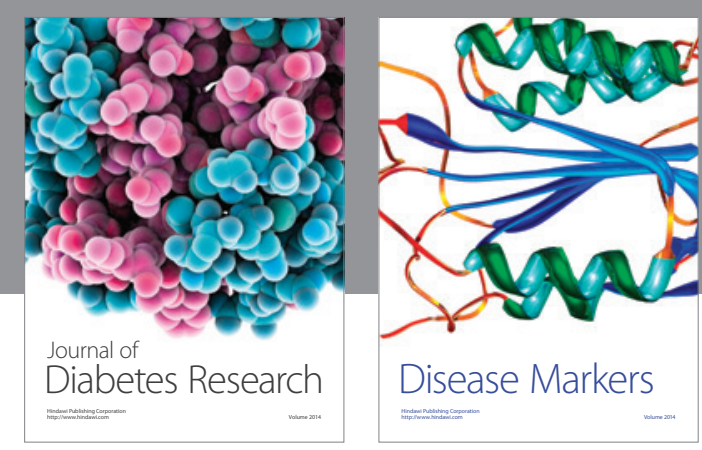

Disease Markers
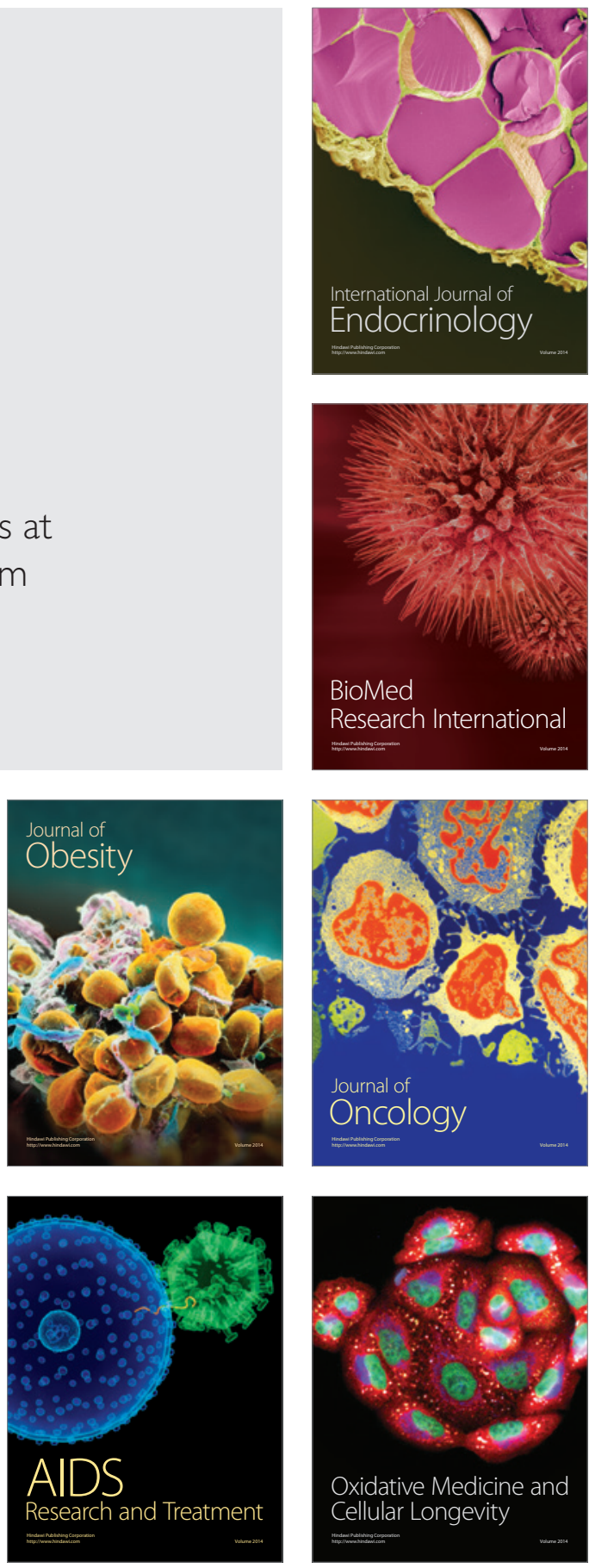